\title{
Satisfaction Survey for a Medication Management Program: Satisfaction Guaranteed?
}

\author{
Priti Flanagan, Suman Kainth, and Lisa Nissen
}

\begin{abstract}
Background: Providing clinical pharmacy services to patients in their homes after discharge from hospital has been reported to reduce health care costs and improve outcomes. The Medication Management Program of the Fraser Health Authority involves pharmacists making home visits to provide clinical pharmacy services to elderly patients who have recently been discharged from hospital and others considered to be at high risk for adverse drug events. Although clinical and economic outcomes of this program have been evaluated, humanistic outcomes such as satisfaction have not been assessed. Moreover, very little evaluation of patient satisfaction with home pharmacy services has been reported in the literature.
\end{abstract}

Objective: To evaluate patient satisfaction with the Medication Management Program.

Methods: A telephone survey instrument, consisting of 7 Likert-scale items and 2 open-ended questions, was developed and administered to patients who received a home pharmacist visit between September 1 and November 23, 2011. In addition to the survey responses, demographic and clinical data for both respondents and nonrespondents were collected.

Results: Of the 175 patients invited to participate in the survey, 103 $(58.9 \%)$ agreed to participate. The majority of respondents agreed or strongly agreed with all of the survey items, indicating satisfaction with the program. For example, 97 (94\%) agreed or strongly agreed that they would recommend the pharmacist home visit program continue to be available, and all 103 (100\%) agreed or strongly agreed that they were satisfied with the pharmacist home visit. Respondents provided some suggestions for program improvement.

Conclusions: The survey findings demonstrate that patients were satisfied with the home clinical pharmacy services offered through the Fraser Health Medication Management Program.

Keywords: pharmacy, satisfaction, home care

\section{RÉSUMÉ}

Contexte : La prestation de services de pharmacie clinique aux patients à domicile après leur congé de l'hôpital réduirait les coûts de soins de santé et améliorerait les résultats selon des rapports. Dans le cadre du Programme de gestion des médicaments de la Fraser Health Authority, des pharmaciens se rendent au domicile de patients âgés ayant récemment obtenu leur congé de l'hôpital et d'autres patients considérés comme à risque élevé d'événements indésirables liés aux médicaments pour leur fournir des services de pharmacie clinique. Bien qu'on ait évalué les incidences cliniques et économiques de tels services, l'aspect humain, comme la satisfaction, n'a pas fait l'objet d'évaluations. En outre, on trouve très peu de données dans la littérature sur l'évaluation de la satisfaction des patients à l'égard des services de pharmacie clinique à domicile.

Objectif : Évaluer la satisfaction des patients à l'égard du Programme de gestion des médicaments.

Méthodes : Un questionnaire à sept énoncés évalués sur une échelle de Likert et à deux questions ouvertes a été développé et utilisé pour réaliser un sondage téléphonique auprès des patients qui avaient reçu la visite à leur domicile d'un pharmacien entre le premier septembre et le 23 novembre 2011. En plus des réponses au sondage, des données démographiques et cliniques ont été collectées à propos des répondants et des non-répondants.

Résultats : Des 175 patients invités à participer au sondage, 103 (58,9 $\%)$ ont accepté. La majorité des répondants étaient d'accord ou tout à fait d'accord avec tous les énoncés du sondage, indiquant ainsi leur satisfaction à l'égard du programme. Par exemple, 97 (94\%) étaient d'accord ou tout à fait d'accord pour recommander que l'on continue d'offrir le programme de pharmacie clinique à domicile et la totalité des $103(100 \%)$ participants étaient d'accord ou tout à fait d'accord pour dire qu'ils étaient satisfaits de la visite du pharmacien à domicile. Les répondants ont formulé quelques suggestions pour améliorer le programme.

Conclusions : Les résultats du sondage indiquent que les patients étaient satisfaits des services de pharmacie clinique à domicile offerts dans le cadre du Programme de gestion des médicaments de la Fraser Health Authority.

Mots clés : pharmacie, satisfaction, soins à domicile

[Traduction par l'éditeur] 


\section{INTRODUCTION}

$\mathrm{P}$ roviding clinical pharmacy services to patients in their homes after discharge from hospital has been reported to reduce readmissions to hospital, visits to the emergency department, and days in hospital during subsequent stays, as well as improving clinical outcomes. ${ }^{1-4}$ On the basis of literature demonstrating the benefits of such service, the Medication Management Program (MMP) was established in 2005 in the Fraser Health Authority, 1 of 6 health authorities in the province of British Columbia, Canada. The MMP is available in the following Fraser Health communities: Burnaby, Surrey, Tri-Cities (Coquitlam, Port Coquitlam, Port Moody), New Westminster, Abbotsford, and White Rock.

The MMP involves pharmacists visiting patients at home to review medication regimens. The program focuses on providing clinical pharmacy services to those at high risk of adverse drug events, such as elderly patients who have recently been discharged from hospital with multiple medications or others who have been identified by health care professionals as being at high risk. Pharmacists' activities within the MMP include identifying and resolving drug-related issues, reconciling the medication regimen, providing patient education, organizing systems to enhance medication adherence, and removing expired, discontinued, or unused medications from the home. Economic and clinical evaluations of the MMP have been conducted ${ }^{5,6}$; however, humanistic outcomes such as patient satisfaction have not been evaluated.
Measuring patient satisfaction is an important component of evaluating health care services. It can provide support for the value of health care services and can also be useful in designing and improving practice. High levels of patient satisfaction with both clinical and dispensing pharmacy functions have been reported in the literature. ${ }^{7-16}$ However, satisfaction with home care pharmacy services has been sparsely reported and has been evaluated with only small numbers of patients. ${ }^{7,8}$ Moreover, to the authors' knowledge, no established, validated survey questionnaire has been published to evaluate patient satisfaction in this setting. A number of validated patient satisfaction surveys have been developed to assess clinical pharmacy services in outpatient settings ${ }^{17-20}$; however, these surveys contain some items that are not relevant to the home care practice of the MMP, and they also fail to capture some key items relevant specifically to evaluation of satisfaction in the home care setting.

The purpose of this study was to evaluate patient satisfaction with the Fraser Health MMP.

\section{METHODS}

\section{Study Population}

All patients for whom a pharmacist conducted a medication review through the MMP between September 1 and November 23, 2011, were eligible for inclusion.

\section{Table 1. Questionnaire Items for Evaluation of Patient Satisfaction with Medication Management Program, Fraser Health Authority}

\begin{tabular}{|c|c|c|}
\hline Item & Original Tool ${ }^{14}$ & As Revised for Current Satisfaction Survey \\
\hline 1 & $\begin{array}{l}\text { The pharmacist provided me with education that } \\
\text { will help me achieve my goals of therapy. }\end{array}$ & Unchanged \\
\hline$\overline{2}$ & $\begin{array}{l}\text { The pharmacist helped me to understand the } \\
\text { intended use (purpose) of my medication(s). }\end{array}$ & Unchanged \\
\hline 3 & $\begin{array}{l}\text { The pharmacist helped me to understand the } \\
\text { intended results (goals of therapy) of my } \\
\text { medication(s). }\end{array}$ & Unchanged \\
\hline$\overline{4}$ & $\begin{array}{l}\text { The pharmacist helped me to understand how } \\
\text { to take my medication(s) safely and correctly. }\end{array}$ & Unchanged \\
\hline 5 & $\begin{array}{l}\text { I feel that my overall health and well-being } \\
\text { improved because of my MTM visit. }\end{array}$ & $\begin{array}{l}\text { I feel that my overall health and well-being } \\
\text { improved because of the home visit I received } \\
\text { from the pharmacist. }\end{array}$ \\
\hline 6 & Health care benefits should include MTM services. & $\begin{array}{l}\text { I would recommend this pharmacist home visit } \\
\text { service continue to be available. }\end{array}$ \\
\hline \multirow[t]{2}{*}{7} & $\begin{array}{l}\text { I would recommend this MTM service to my } \\
\text { family and friends. }\end{array}$ & $\begin{array}{l}\text { Overall, I was satisfied with the pharmacist home } \\
\text { visit. }\end{array}$ \\
\hline & $\begin{array}{l}\text { Space for respondents to provide written } \\
\text { comments and suggestions about the } \\
\text { MTM program }\end{array}$ & $\begin{array}{l}\text { Open-ended questions: } \\
\text { 1. Please describe up to } 3 \text { things you like most } \\
\text { about the pharmacist home visit program } \\
\text { 2. Please describe up to } 3 \text { ways in which you } \\
\text { would improve the pharmacist home visit } \\
\text { program }\end{array}$ \\
\hline
\end{tabular}

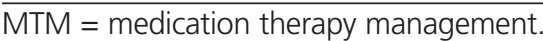


Over the past 3 years, MMP pharmacists have provided service to, on average, 1215 patients (range 1129 to 1351) per year. The intention was to survey consecutive patients seen over a 2- to 3-month period to ensure that at least $10 \%$ of the total annual patient population was captured. It was anticipated that this approach, involving an intensive review and follow-up period, would provide a convenience sample for the study, while also ensuring a good survey response rate.

The majority of patients seen by the pharmacists within the MMP are 65 years of age or older, have been recently discharged from hospital (within the previous 7 days), and are taking 6 or more regularly scheduled medications at the time of discharge. MMP pharmacists may also receive referrals from other health care practitioners, for example, nurses, hospital pharmacists, and physicians.

Ethics approval for this study was provided by the Fraser Health Research Ethics Board (approval number FHREB 2011-082).

\section{Survey Instrument}

The survey instrument developed for this study was based on existing literature, in particular a tool developed by Ramalho de Oliveira and others, ${ }^{14}$ and was evaluated for face and content validity by the MMP pharmacists. Of the 7 items that Ramalho de Oliveira and others ${ }^{14}$ used to assess patient satisfaction, items 1 to 5 and item 7 were used for the current survey instrument (numbered as items 1 through 6) either identically or with modification to reflect the MMP home care setting (see Table 1). Item 7 in the current survey asked respondents about overall satisfaction with the MMP. Respondents were asked to rate each of these 7 items on the Likert-type scale used by Ramalho de Oliveira and others ${ }^{14}(1=$ strongly agree, 2 = somewhat agree, $3=$ neither disagree nor agree [neutral], $4=$ somewhat agree, and $5=$ strongly agree) and to answer 2 open-ended questions.

Patients who received service from an MMP pharmacist during the study period, or their caregivers, were contacted by phone within 7 days with an invitation to participate in the study. If they consented to participate, the survey questions were posed over the phone. Patients or caregivers who declined participation or who could not be reached by the interviewer after 3 tries were categorized as nonrespondents. All surveys were conducted by the same research assistant and took place between September 15 and November 24, 2011.

\section{Data Collection}

Demographic variables for the patient (age, city of residence, and sex), as well as number of medications, number and types of drug-related problems identified by the pharmacist, and whether or not the patient had had a recent hospital stay, were collected for both respondents and nonrespondents. In addition, the interviewer recorded whether the patient or a caregiver responded to the survey.

\section{Data Analysis}

Demographic data and responses to the 7 Likert-scale items on the survey instrument were analyzed using descriptive statistics in Microsoft Excel (Redmond, Washington). The demographic characteristics of the study population are reported as means and ranges as appropriate. Responses to open-ended questions were evaluated by looking for common themes.

\section{RESULTS}

A total of 1257 individual patients received the MMP service during 2011, the year in which this satisfaction survey was performed; of these, 175 (13.9\%) received the MMP service during the specified study period and were invited to respond to the satisfaction survey, and 103 (58.9\%) patients or their caregivers agreed to participate.

The majority of the patients eligible for inclusion in this evaluation came from Burnaby and Surrey, which together accounted for more than half of both the respondent and nonrespondent groups (Table 2). On average, those who received the MMP service had more than 3 drug-related problems identified by the pharmacist, and the majority of them were seen as a result of recent discharge from hospital.

The majority of respondents agreed or strongly agreed with all items in the survey, including item 6 , recommending that the program continue to be available (Table 3 ). Among the 103 survey responses, there was only one refusal to answer a specific question (item 5). Similarly, for most items, very few respondents $(0 \%-5.8 \%)$ had no opinion. The exception was item 5, asking whether overall health and well-being had improved as a result of the pharmacist home visit; for this question, 34 (33.0\%) of the respondents had no opinion. The reason given by respondents who had no opinion was that they thought there had not been enough time to determine if their health and well-being had improved as a result of the service.

The first open-ended question asked respondents to describe 3 things they liked most about the MMP, to which 76 $(73.8 \%)$ of patients or caregivers responded. The primary theme in the responses related to communication: respondents felt that the pharmacists had been easy to understand and that they had used everyday language rather than medical jargon, which facilitated patients' understanding. A second theme related to resources provided by the pharmacists, such as a medication schedule, an action plan, and a medication information vial for use in emergency situations (a list of the patient's medications prepared by the pharmacist and placed in a medi- 
Table 2. Demographic and Clinical Characteristics of Study Population

\begin{tabular}{|c|c|c|c|c|}
\hline \multirow{3}{*}{$\begin{array}{l}\text { Characteristic } \\
\text { Age of patient (years), mean }\end{array}$} & \multicolumn{4}{|c|}{ Group; No. (\%)* } \\
\hline & \multicolumn{2}{|c|}{ Respondents $(n=103)$} & \multicolumn{2}{|c|}{ Nonrespondents $(n=72)$} \\
\hline & 79.1 & $(65-97)$ & 79.2 & $(50-94)$ \\
\hline \multicolumn{5}{|l|}{ Sex of patient } \\
\hline Male & 47 & $(45.6)$ & 32 & (44.4) \\
\hline Female & 56 & (54.4) & 40 & (55.6) \\
\hline Caregiver responding on behalf of patient & 34 & $(33.0)$ & 25 & $(34.7)$ \\
\hline No. of medications, mean (range) & 10.5 & $(4-22)$ & 9.3 & $(2-9)$ \\
\hline No. of drug-related problems, mean (range) & 3.4 & $(0-12)$ & 3.3 & $(0-9)$ \\
\hline Recent admission to hospital & 87 & $(84.5)$ & 58 & $(80.6)$ \\
\hline \multicolumn{5}{|l|}{ City of residence } \\
\hline Burnaby & 34 & (33.0) & 19 & (26.4) \\
\hline New Westminster & 10 & $(9.7)$ & 9 & (12.5) \\
\hline Tri-Cities & 14 & (13.6) & 12 & $(16.7)$ \\
\hline Delta & 3 & $(2.9)$ & 4 & $(5.6)$ \\
\hline Surrey & 27 & $(26.2)$ & 21 & $(29.2)$ \\
\hline Abbotsford & 14 & (13.6) & 7 & $(9.7)$ \\
\hline White Rock & 1 & $(1.0)$ & 0 & (0) \\
\hline
\end{tabular}

*Except where indicated otherwise.

Table 3. Results of Patient Satisfaction Survey Regarding Medication Management Program, Fraser Health Authority

\begin{tabular}{|c|c|c|c|c|c|c|c|}
\hline \multirow[b]{2}{*}{ Statement } & \multicolumn{6}{|c|}{ Score; No. $(\%)$ of Respondents $(n=103)$} & \multirow[b]{2}{*}{ Refused } \\
\hline & $\begin{array}{l}\text { Strongly } \\
\text { Disagree }\end{array}$ & Disagree & Neutral & Agree & $\begin{array}{l}\text { Strongly } \\
\text { Agree }\end{array}$ & $\begin{array}{c}\text { No } \\
\text { Opinion }\end{array}$ & \\
\hline $\begin{array}{l}\text { 1. The pharmacist provided me with } \\
\text { education that will help me achieve my } \\
\text { goals of therapy. }\end{array}$ & $0(0)$ & $0 \quad(0)$ & $2(1.9)$ & $17(16.5)$ & $81(78.6)$ & $3 \quad(2.9)$ & $0 \quad(0)$ \\
\hline $\begin{array}{l}\text { 2. The pharmacist helped me to } \\
\text { understand the intended use (purpose) } \\
\text { of my medicines. }\end{array}$ & $0(0)$ & $0 \quad(0)$ & $0(0)$ & $8 \quad(7.8)$ & $94(91.3)$ & $(1.0)$ & $0 \quad(0)$ \\
\hline $\begin{array}{l}\text { 3. The pharmacist helped me to } \\
\text { understand the intended results (goals } \\
\text { of therapy) of my medicines. }\end{array}$ & $0(0)$ & $0 \quad(0)$ & $3(2.9)$ & $15(14.6)$ & $79(76.7)$ & $6 \quad(5.8)$ & $0 \quad(0)$ \\
\hline $\begin{array}{l}\text { 4. The pharmacist helped me to } \\
\text { understand how to take my medicines } \\
\text { safely and correctly. }\end{array}$ & $0(0)$ & $0 \quad(0)$ & $2(1.9)$ & $6 \quad(5.8)$ & $94(91.3)$ & $(1.0)$ & $0 \quad(0)$ \\
\hline $\begin{array}{l}\text { 5. I feel that my overall health and well- } \\
\text { being improved because of the home } \\
\text { visit I received from the pharmacist. }\end{array}$ & $2(1.9)$ & $3(2.9)$ & $7(6.8)$ & $15(14.6)$ & $41(39.8)$ & $34(33.0)$ & $1(1.0)$ \\
\hline $\begin{array}{l}\text { 6. I would recommend this pharmacist } \\
\text { home visit service continue to be availabl }\end{array}$ & $\begin{array}{ll}1(1.0) \\
\text { e. }\end{array}$ & $0 \quad(0)$ & $2(1.9)$ & $5 \quad(4.9)$ & $92(89.3)$ & $(2.9)$ & $0 \quad(0)$ \\
\hline $\begin{array}{l}\text { 7. Overall, I was satisfied with the } \\
\text { pharmacist home visit. }\end{array}$ & $0 \quad(0)$ & $\begin{array}{ll}0 & (0)\end{array}$ & $0 \quad(0)$ & $5 \quad(4.9)$ & $98(95.1)$ & (0) & $0 \quad(0)$ \\
\hline
\end{tabular}

*Except where indicated otherwise.

caton vial, for ready access if emergency services are required), which were appreciated. One patient noted that seeing the pharmacist in the home environment allowed him to feel more at ease, because everything was more familiar and nonintrusive. The same patient said that the MMP was good for immobile patients and those who use wheelchairs, have difficulty walking, or generally have difficulty getting out of the house. Another patient reported that she felt like she was being cared for, rather than just another number on the ward.
For the second open-ended question, which asked what improvements could be made, $18(17.5 \%)$ of patients or caregivers responded. The most common theme was the suggestion to have more pharmacist home visits. The second most common suggestion was to offer phone visits instead of home visits. Finally, some respondents suggested that there should be an easier way to contact the pharmacist after the visit. Many respondents reported that the MMP was beneficial, that they were not expecting much to begin with, and hence that they had no suggestions for improvement. 


\section{DISCUSSION}

The results of this study indicate that respondents had a high level of satisfaction with the MMP. These results are comparable to the findings of other evaluations of patient satisfaction with pharmacy services. ${ }^{7-16}$ They will be used to support the continuance of the MMP and to advocate for expansion of the program throughout the Fraser Health Authority. Because respondents provided few suggestions for improvement, there was little information to guide changes to the way in which the program is delivered. Interestingly, although many respondents supported having this program available, some suggested that the visits be conducted by phone rather than in person. This indicates that for some, the level of service offered through this program was more than was needed. Further work on refining the criteria for program inclusion will be undertaken to ensure that the service is delivered to those for whom it is warranted.

The response rate for this study, in which the satisfaction survey was administered over the phone (58.9\%), was similar to rates for previous similar surveys reported in the literature. These response rates have ranged from $28 \%$ to $88.4 \%$ for mail surveys, ${ }^{7,9,11,13-16,18}$ from $82.1 \%$ to $100 \%$ for in-person interviews, ${ }^{10,17}$ from $76.6 \%$ to $90.4 \%$ for self-administered surveys in a pharmacy or clinic, ${ }^{19,20}$ and $59 \%$ for a telephone interview. ${ }^{8}$

Although patient satisfaction with pharmacy services has been reported as high, most evaluations of satisfaction have not used an experimental design. Among evaluations conducted by means of comparison trials, there have been discrepancies, with some authors reporting higher patient satisfaction among those who received the intervention being studied than among those who received no intervention (i.e., usual care), ${ }^{12,16}$ and other authors reporting no difference in satisfaction between those who received the pharmacy services intervention and those who received usual care. ${ }^{21,22}$ In both of the studies in which patient satisfaction with pharmacy services was higher in the intervention group than the nonintervention group, the survey was developed specifically for the evaluation and was based on literature and the project itself. ${ }^{12,16}$ In one of the studies in which satisfaction was not higher in the intervention group, ${ }^{22}$ the survey used to assess patient satisfaction ${ }^{23}$ had been developed to assess health services in general, not pharmacy services in particular. In the other study that reported no comparative benefit of the intervention, in terms of satisfaction, ${ }^{21}$ the tool used to measure satisfaction was the General Satisfaction with Pharmacy Services Scale, a satisfaction questionnaire that has been evaluated for reliability and validity. ${ }^{192426}$ The items in this survey evaluate domains related to drug distribution and clinical services. ${ }^{24-26}$

To our knowledge, there are no validated surveys for evaluating satisfaction with clinical pharmacy services provided in a home care setting, and the studies that have evaluated this outcome have not clearly described the survey instrument used. ${ }^{78}$ For these reasons, we chose to develop an instrument specific to our setting. Although this instrument was based largely on one developed to evaluate satisfaction with clinical pharmacy services in an ambulatory setting, ${ }^{14}$ it was adapted to make it relevant to the home care setting. Ramalho de Oliveira and others ${ }^{14}$ reported a response rate of $28 \%$ from 1132 mailed surveys and a high level of satisfaction among patients who received the services and responded to the survey. Relative to the current MMP study, the study by Ramalho de Oliveira and others ${ }^{14}$ had a different setting for clinical pharmacy services and included younger patients (aged 21 years and older). In addition, those authors administered their survey by mail, after more interaction with the pharmacist (2 visits) and over a longer period of time (July to December 2008). Despite these differences, most of their results were consistent with ours. However, $95.3 \%$ of their respondents, but only $54.4 \%$ in our study, agreed or strongly agreed that their overall health and had well-being improved as a result of the pharmacist intervention. This difference likely relates to the fact that many patients in the current study felt it was too soon to judge any improvement.

\section{Limitations}

Although this study has provided valuable information about patients' experience with the MMP, there were some limitations. The evaluation of patient satisfaction related to clinical services provided by the MMP pharmacists. These services were not provided as part of an experimental trial, and therefore satisfaction was not evaluated according to an experimental design. Hence, it is unknown if receipt of this program resulted in comparatively greater satisfaction than would have achieved without the service or with a different service delivery model. The study was conducted from September to November, and it was assumed that the responses would be the same throughout the year; however, the potential for seasonal variation is unknown. Also, the respondents were mainly from 2 of the communities in which the MMP service was offered and may not represent all those who receive the service, given the potential for regional variation.

The representativeness of the results may also have been hampered by the sample size. Although more than $10 \%$ of patients who received a visit from an MMP pharmacist over the course of the year were invited to participate, the number who responded to the survey (103) was less than $10 \%$. Given that the respondent and nonrespondent groups were similar in terms of demographic and clinical information, it was assumed that those who responded were representative of the group at large. Another limitation is that one-third of the respondents 
were family members or caregivers, rather than the patients themselves. We have assumed that the answers given by these representatives were the same as the patients would have given, but this may not have been the case.

Finally, there may have been situations in which communication was a barrier, which would limit the validity of the results. For example, the Likert scale options may have caused confusion, especially among those for whom English is a second language. The extent to which respondents had difficulty understanding the survey is unknown.

\section{CONCLUSION}

Overall, the results of this survey demonstrate that patients were satisfied with the clinical pharmacy service offered through the Fraser Health MMP.

\section{References}

1. Stewart S, Pearson S, Luke CG, Horowitz JD. Effects of home-based intervention on unplanned readmissions and out-of-hospital deaths. $J$ Am Geriatr Soc. 1998;46(2):174-80.

2. Stewart S, Pearson S, Horowitz JD. Effects of a home-based intervention among patients with congestive heart failure discharged from acute hospital care. Arch Intern Med. 1998;158(10):1067-72.

3. Naunton M, Peterson GM. Evaluation of home-based follow-up of highrisk elderly patients discharged from hospital. J Pharm Pract Res. 2003;33(3): 176-82.

4. Jackson SL, Peterson GM, Vial JH, Jupe DML. Improving the outcomes of anticoagulation: an evaluation of home follow-up of warfarin initiation. J Intern Med. 2004;256(2):137-44.

5. Flanagan P, Virani A, Baker W, Roelants H. Pharmacists making house calls: innovative role or overkill? Can J Hosp Pharm. 2010;63(6):412-9.

6. Flanagan PS, Pawluk S, Bains S. Opportunities for medication-related support after discharge from hospital. Can Pharm J. 2010;143(4):170-5.

7. Peterson GM, Fitzmaurice KD, Naunton M, Stewart K, Krum H. Impact of pharmacist-conducted home visits on the outcomes of lipid-lowering drug therapy. J Clin Pharm Ther. 2004;29(1):23-30.

8. MacAulay S, Saulnier L, Gould O. Provision of clinical pharmacy services in the home to patients recently discharged from hospital: a pilot project. Can J Hosp Pharm. 2008;61(2):103-13.

9. Zed PJ, Filiatrault L. Clinical outcomes and patient satisfaction of a pharmacistmanaged, emergency department-based outpatient treatment program for venous thromboembolic disease. CJEM. 2008;10(1):10-7.

10. Wilkinson ST, Pal A, Couldry RJ. Impacting readmission rates and patient satisfaction: results of a discharge pharmacist pilot program. Hosp Pharm. 2001;46(11):876-83.

11. Collins C, Kramer A, O’Day ME, Low MB. Evaluation of patient and provider satisfaction with a pharmacist-managed lipid clinic in a Veterans Affairs medical center. Am J Health Syst Pharm. 2006;63(18):1723-7.

12. Community Pharmacy Medicines Management Project Evaluation Team. The MEDMAN study: a randomized controlled trial of community pharmacy-led medicines management for patients with coronary heart disease. Fam Pract 2007;24(2):189-200.

13. Holsclaw SL, Olson KL, Hornak R, Denham AM. Assessment of patient satisfaction with telephone and mail interventions provided by a clinical pharmacy cardiac risk reduction service. J Manag Care Pharm. 2005;11(5):403-9.

14. Ramalho de Oliveira D, Brummel AR, Miller DB. Medication therapy management: 10 years of experience in a large integrated health care system. J Manag Care Pharm. 2010;16(3):185-95.

15. Taylor J, Semchuk W, Neubauer S, Kuz G. Patient satisfaction with a smoking cessation program in community pharmacies. Can Pharm J. 2003; 136(5):30-4.
16. Tinelli M, Bond C, Blenkinsopp A, Jaffray M, Watson M, Hannaford P; Community Pharmacy Medicines Management Evaluation Team. Patient evaluation of a community pharmacy medications management service. Ann Pharmacother. 2007;41(12):1962-70.

17. Gourley GK, Gourley DR, La Monica Rigolosi E, Reed P, Solomon DK, Washington E. Development and validation of the pharmaceutical care satisfaction questionnaire. Am J Manag Care. 2001;7(5):461-6.

18. Larson LN, Rovers JP, MacKeigan LD. Patient satisfaction with pharmaceutical care: update of a validated instrument. J Am Pharm Assoc. 2002;42(1):44-50.

19. Pinto SL, Sahloff EG, Ramasamy A. Evaluating the validity and reliability of a modified survey to assess patient satisfaction with mail-order and community pharmacy settings. J Pharm Pract. 2010;23(2):128-34.

20. Traverso ML, Salamano M, Botta C, Colautti M, Palchik V, Pérez B. Questionnaire to assess patient satisfaction with pharmaceutical care in Spanish language. Int J Qual Health Care. 2007;19(4):217-24.

21. Tsuyuki RT, Johnson JA, Teo KK, Simpson SH, Ackman ML, Biggs RS, et al. A randomized trial of the effect of community pharmacist intervention on cholesterol risk management: the Study of Cardiovascular Risk Intervention by Pharmacists (SCRIP). Arch Intern Med. 2002;162(10):1149-55.

22. Nazareth I, Burton A, Shulman S, Smith P, Haines A, Timberall H. A pharmacy discharge plan for hospitalized elderly patients - a randomized controlled trial. Age Ageing. 2001;30(1):33-40.

23. Larsen DL, Attkisson CC, Hargreaves WA, Nguyen TD. Assessment of client/patient satisfaction: development of a general scale. Eval Program Plann. 1979;2(3):197-207.

24. Larson LN, MacKeigan LD. Further validation of an instrument to measure patient satisfaction with pharmacy services. J Pharm Market Manage. 1994; 8(1):125-39.

25. MacKeigan LD, Larson LN. Development and validation of an instrument to measure patient satisfaction with pharmacy services. Med Care. 1989; 27(5):522-36.

26. Johnson JA, Coons SJ, Hays RD. The structure of satisfaction with pharmacy services. Med Care. 1998;36(2):244-50.

Priti Flanagan, BSP, ACPR, PharmD, is Coordinator of Community Pharmacy Programs, Fraser Health, Langley, British Columbia, and Clinical Assistant Professor, University of British Columbia, Vancouver, British Columbia.

Suman Kainth, BSCPharm,ACPR is a Clinical Pharmacist with Community Pharmacy Programs, Fraser Health, Burnaby Home Health, Burnaby, British Columbia.

Lisa Nissen, PhD, is Professor and Head of the School of Clinical Sciences, Queensland University of Technology, Brisbane, Queensland, Australia.

Competing interests: Priti Flanagan has received speakers' fees and payment for educational presentations on topics unrelated to this article from the Canadian Society of Hospital Pharmacists (CSHP), Pharmaceutical Services Division, and payment of travel expenses from the CSHP Harrison Pharmacy Management Seminar. No competing interests declared by Suman Kainth or Lisa Nissen.

\section{Address correspondence to:}

Dr Priti Flanagan

Regional Pharmacy Administration

8521 198A Street

Langley BC V2Y OA1

e-mail: priti.flanagan@fraserhealth.ca

\section{Acknowledgement}

The authors would like to acknowledge Christine Chow, who worked as a research assistant on this project and was involved with the data collection. 